University of Nebraska - Lincoln

DigitalCommons@University of Nebraska - Lincoln

Faculty Publications, Department of Psychology

Psychology, Department of

December 1998

\title{
Morphine-Conditioned Changes in Locomotor Activity: Role of the Conditioned Stimulus
}

Rick A. Bevins

University of Nebraska-Lincoln, rbevins1@unl.edu

Michael T. Bardo

University of Kentucky

Follow this and additional works at: https://digitalcommons.unl.edu/psychfacpub

Part of the Psychiatry and Psychology Commons

Bevins, Rick A. and Bardo, Michael T., "Morphine-Conditioned Changes in Locomotor Activity: Role of the Conditioned Stimulus" (1998). Faculty Publications, Department of Psychology. 291.

https://digitalcommons.unl.edu/psychfacpub/291

This Article is brought to you for free and open access by the Psychology, Department of at DigitalCommons@University of Nebraska - Lincoln. It has been accepted for inclusion in Faculty Publications, Department of Psychology by an authorized administrator of DigitalCommons@University of Nebraska - Lincoln. 
Published in Experimental and Clinical Psychopharmacology, 6:2 (1998), pp. 131-138; doi: 10.1037/1064-1297.6.2.131

Copyright (C) 1998 American Psychological Association. Used by permission. "This article may not exactly replicate the final version published in the APA journal. It is not the copy of record.” http:/www.apa.org/journals/

Submitted October 7, 1997; revised December 11, 1997; accepted December 18, 1997.

\title{
Morphine-Conditioned Changes in Locomotor Activity: Role of the Conditioned Stimulus
}

\author{
Rick A. Bevins, Department of Psychology, University of Nebraska-Lincoln \\ Michael T. Bardo, Department of Psychology, University of Kentucky
}

\begin{abstract}
When a multisensory environment was reliably paired with morphine $(2 \mathrm{mg} / \mathrm{kg})$ in rats, that environment, in a drug-free test, evoked a hyperactive conditioned response (CR). When an olfactory cue (banana odor) was the only stimulus element reliably paired with morphine, it also elicited a hyperactive CR. However, a gustatory cue (saccharin solution) evoked a hypoactive CR. This taste-elicited decrease in activity was dose dependent; morphine at 2 and $4 \mathrm{mg} / \mathrm{kg}$ conditioned hypoactivity, whereas a higher dose $(8 \mathrm{mg} / \mathrm{kg})$ did not. A robust conditioned saccharin aversion occurred only at the highest dose of morphine, suggesting disassociation between the hypoactive CR and taste aversion. A taste cue present during context conditioning also prevented either acquisition or expression of the hyperactive CR to the context. The modality of the conditioned stimulus is a critical determinant of the form of the CR in a morphine locomotor conditioning paradigm.
\end{abstract}

Drugs that are abused have a wide range of effects on the behavior and the biology of an organism. Some of these effects are enhanced with drug experience. Of interest to us is the increase in activity seen in rats after repeated administration of morphine (e.g., Babbini \& Davis, 1972). This morphine-induced enhancement of activity, termed locomotor sensitization, has received much attention by researchers in the drug abuse area. One reason is the apparent overlap of the neural mechanism of locomotor sensitization and the rewarding and motivational effects of drugs (Kalivas \& Stewart, 1991; Wise \& Bozarth, 1987).

Interestingly, if rats receive a distinct environmental cue (context) reliably paired with morphine, that context, in the absence of any morphine administration, will come to evoke an increase in activity relative to that in control rats (Mucha, Volkovskis, \& Kalant, 1981; Neisewander \& Bardo, 1987). It is generally believed that Pavlovian conditioning mechanisms are responsible for this context-elicited hyperactivity (Stewart, 1992a, 1992b). According to this formulation, the context is the conditioned stimulus (CS) and the morphine is the unconditioned stimulus (US). The increase in activity evoked by the context alone after repeated pairings with the morphine US is termed the conditioned response (CR).

Theories of drug use and addiction based on withdrawal, reward, and/or incentive-motivational mechanisms often explain drug taking and relapse by invoking Pavlovian conditioning

This research was supported by U.S. Public Health Service Grants DA05312, DA07746, and DA05623.

We are grateful to P. Kraemer, P. Robinet, and J. Valone for their comments on an earlier version of this article. We also thank K. Shanmugham for conducting pilot work and M. Marion for help in conducting some of the experiments reported here.

Corresponding author: Rick A. Bevins, Department of Psychology, University of Nebraska-Lincoln, Lincoln, Nebraska 68588-0308; email rbevins@unlinfo.unl.edu. processes (O'Brien, Childress, McLellan, \& Ehrman, 1992; Robinson \& Berridge, 1993; Schulteis \& Koob, 1996; Siegel, 1988; Stewart, 1992a; Wise \& Bozarth, 1987). For instance, Robinson and Berridge recently theorized that drug seeking, uncontrollable drug taking, and relapse following treatment for drug abuse may be attributed to the associative (Pavlovian) control of environmental stimuli acquired during repeated exposure to the drug in the presence of those stimuli. Despite this reliance on conditioning mechanisms, the behavioral and neural processes involved in the acquisition and the expression of conditioned drug effects have received little empirical attention in comparison to unconditioned drug effects (cf. Stewart, 1992b).

Much of the research on Pavlovian drug conditioning has made use of multisensory environmental contexts as the tobe-conditioned stimulus. Because a contextual CS may include visual, auditory, thermal, olfactory, gustatory, and tactile stimulus elements, it is unclear which element or combination of elements is necessary or sufficient to establish conditioning. Few explicit attempts have been made to identify and study effective stimulus elements. One recent exception is a study by Schwarz-Stevens and Cunningham (1993; see also Schwarz and Cunningham (1990). They found that a discrete light-noise compound CS paired with intravenous morphine in rats elicited increases in heart rate and body temperature in the absence of any drug. Furthermore, the degree of conditioning was sensitive to the CS duration after morphine administration was terminated. It appears that tactile cues can also serve as effective CS in Pavlovian drug conditioning. Vezina and Stewart (1987), for example, demonstrated that rats preferred a tactile floor cue previously paired with morphine over one paired with saline. Also, locomotor activity appeared to increase directly with the amount of morphine-paired flooring that was present during testing. Us- 
ing an apomorphine-conditioned stereotypy paradigm, Ferger and Kuschinsky (1995) found that an olfactory cue, but not a tactile or an auditory cue, elicited conditioned licking and sniffing responses.

The work just described demonstrates that various stimulus types (elements) can serve as a CS in Pavlovian drug conditioning experiments. To our knowledge, however, no one has examined the ability of different stimulus elements to serve as $\mathrm{CS}$ in a morphine-conditioned locomotor paradigm. Thus, in this series of experiments, we examined the ability of a gustatory cue (saccharin solution) and an olfactory cue (banana extract) to function as a CS in this situation.

\section{Method}

\section{Subjects}

The subjects were 95 male Sprague-Dawley rats obtained from Harlan Industries (Indianapolis, IN). They weighed 200 to $225 \mathrm{~g}$ on arrival and were handled at least twice before the start of each experiment. Rats were housed individually in a hanging stainless steel cage in a colony room on a 12-hr light-dark cycle. Rats in Experiment 3 had free access to water in their home cages; fluid availability was restricted to $15 \mathrm{~min}$ daily for rats in Experiments 1, 2a, 2b, and 2c. Food was available continuously in the home cages.

\section{Apparatus and Drug}

Four wooden boxes were used in Experiment 1. All four boxes were located in a laboratory room isolated from the home colony room. The laboratory room was illuminated with two fluorescent ceiling lights. A white-noise generator that ran continuously masked external noises. The inside walls of two of the boxes were painted black; the inside walls of the other two boxes were painted white. Only the white boxes were used in Experiments 2a, 2b, 2c, and 3.

The inside dimensions (length $\times$ width $\times$ height) of each black box were $30.1 \times 27.6 \times 45 \mathrm{~cm}$. The floor was made of wire mesh $(7 \times$ $7 \mathrm{~mm}$ ), and cedar chips lined the litter tray. Fluids were presented in 100-ml graduated water bottles mounted on the outside of each box so that the metal sipper tube was inserted into a hole that entered the inside of the box. The sipper tube, centered on one wall, was $3 \mathrm{~cm}$ above the mesh floor. Consumption was measured to the nearest milliliter. Locomotor activity was not monitored in the black boxes (see below).

The inside dimensions of each white box were $30.3 \times 27.6 \times 42.7$ $\mathrm{cm}$. Wire mesh $(14 \times 14 \mathrm{~mm})$ served as flooring, and the litter tray was lined with pine wood chips. Fluids were presented in a manner similar to that for the black boxes, except that the drinking tube was mounted $5.5 \mathrm{~cm}$ from an end wall and $4 \mathrm{~cm}$ above the mesh floor. The white boxes were equipped with two photobeam detector units. The units were mounted $4 \mathrm{~cm}$ above the floor so that they divided the chambers into four equal quadrants. Solid-state equipment located in an adjacent room automatically recorded the number of photobeam breaks during preset intervals. In all of the experiments, activity on the test day was assessed in the automated white locomotor boxes.

The taste CS was a $0.1 \%(\mathrm{wt} / \mathrm{vol})$ sodium saccharin solution. The olfactory cues in Experiment 3 were a banana odor (Imitation Banana Flavor; Kroger) and orange odor (Pure Orange Extract; Kroger). At the end of each day, the boxes were cleaned with a solution of $20 \%$ acetic acid and $80 \%$ tap water.

Morphine sulfate (National Institute on Drug Abuse, Rockville, MD) was dissolved in saline $(0.9 \% \mathrm{NaCl})$. All injections were sub- cutaneous at a volume of $1 \mathrm{ml} / \mathrm{kg}$. Morphine dosages were calculated on the basis of the salt form of the drug.

\section{Procedure}

Conditioning for all experiments included 8 morphine injection days alternating with 8 saline injection days. On each of the 16 days, a rat was injected with the appropriate solution (morphine or saline) and then placed in the activity box and allowed 15 min of access to either tap water or $0.1 \%$ saccharin solution (Experiments $1,2 \mathrm{a}, 2 \mathrm{~b}$, and $2 \mathrm{c}$ ) or $15 \mathrm{~min}$ of exposure to either banana or orange odor (Experiment 3). On the day after the last conditioning trial, a CS-alone test was administered. CS-alone testing consisted of a saline injection followed by placement in the white locomotor box with the CS present. The CS-alone test allowed us to determine whether the paired stimulus acquired the ability to change ongoing activity in the absence of any drug (i.e., evidence of conditioning).

\section{Experiment 1}

The purpose of Experiment 1 was to examine the ability of a context, a taste, or a compound stimulus of context plus taste to serve as a CS in a morphine-conditioned locomotor paradigm. Rats were assigned to one of four treatment groups. All groups were exposed equally to the black and white activity boxes, to the two fluids (tap water and $0.1 \%$ saccharin solution), and to morphine ( $2 \mathrm{mg} / \mathrm{kg}$ ) and saline. However, which stimuli were paired with morphine and saline differed for each group. The group names denote which stimuli were paired with morphine for conditioning and then assessed in a no-drug test in the white context. Group CXT+SAC $(n=5)$ had the white context and the saccharin solution paired with morphine; the black box and tap water were paired with saline. A second group, group CXT $(n=3)$, had the white context and tap water paired with morphine; the black box and saccharin were paired with saline. Another group of rats, group SAC $(n=3)$, had the black box and saccharin paired with morphine; the white context and tap water were paired with saline. The last group was an unpaired control (group UNP; $n=$ 4) that had the black box and water paired with morphine; the white context and saccharin were paired with saline. All groups were tested for $75 \mathrm{~min}$ in the white box containing the saccharin solution about $24 \mathrm{hr}$ after the last conditioning trial. The 75 -min CS-alone test was divided into two time periods: the first $15 \mathrm{~min}$ (duration of each conditioning trial) and an additional $60 \mathrm{~min}$. The number of photobeam breaks was recorded for the first $15 \mathrm{~min}$; the counters were then reset, and breaks were recorded for another $60 \mathrm{~min}$.

\section{Experiments $2 a, 2 b$, and $2 c$}

These experiments were designed to assess the effect of changing the morphine dose on conditioned changes in locomotor activity for a saccharin CS. In Experiments 2a, 2b, and 2c, we tested morphine doses of 2, 4, and $8 \mathrm{mg} / \mathrm{kg}$, respectively. The procedures from Experiment 1 were modified so that all conditioning and testing were conducted in the automated white locomotor boxes. There were 6 preexposure days before the start of conditioning. Each preexposure day consisted of $15 \mathrm{~min}$ of access to water in the white box; no injections were given. Preexposing the context cues (white box) decreased the likelihood that the context would serve as a CS and acquire the ability to elicit a hyperactive CR (see Ayres, Philbin, Cassidy, Bellino, \& Redlinger, 1992; Lubow, 1973). Moreover, 6 preexposure days allowed water consumption to stabilize before the conditioning phase. For each experiment, rats were randomly assigned to one of two groups (referred to as group paired and group unpaired; $n=10$ per 
group), with the restriction that activity and water intake did not differ statistically between the groups on the last preexposure day. The conditioning phase consisted of 8 saccharin days and 8 intervening water days. On the saccharin days, group paired received an injection of morphine $(2,4$, or $8 \mathrm{mg} / \mathrm{kg})$ followed immediately by $15 \mathrm{~min}$ of access to $0.1 \%$ saccharin CS in the white box. On the water days, group paired received an injection of saline followed immediately by 15 min of access to water in the white box. Note that the intervening water days provided an extinction trial for context cues (i.e., weakened conditioning to the context, if any occurred; Pavlov, 1927; Rescorla \& Wagner, 1972). Hence, only the saccharin taste was reliably paired with morphine for group paired. In each experiment, the control group (group unpaired) underwent the same procedure, except that morphine was given on water days and saline was given on saccharin days. Testing for conditioned changes in locomotor activity was identical to that in Experiment 1.

\section{Experiment 3}

The purpose of Experiment 3 was to examine whether a discrete odor cue could serve as a CS in morphine locomotor activity conditioning. The experimental protocol was similar to that in Experiment $2 \mathrm{a}$, except for the changes noted below. On the 2 days before the conditioning phase, each rat was preexposed to the white locomotor box for $30 \mathrm{~min}$. Overall preexposure was decreased in this experiment because stabilization of fluid consumption was not required. For the 8 conditioning days, each rat in group paired $(n=10)$ received a morphine injection of $2 \mathrm{mg} / \mathrm{kg}$ followed immediately by a 15 -min presentation of a banana odor in the white context. Group unpaired $(n=10)$ received saline on the banana odor days. On the 8 alternating days, rats were given the opposite injection and then exposed to an orange odor for $15 \mathrm{~min}$ in the white context. On the test day, each rat was injected with saline and then placed in a white context for $30 \mathrm{~min}$ with the banana odor present. The test duration for this experiment was shortened relative to those in the other experiments because we were concerned that the banana extract, which contained 47\% (vol/vol) alcohol, would evaporate, thus making the odor CS dissipate across the test. During the conditioning and testing phases, new odorant $(1 \mathrm{ml})$ was applied to the bedding before each rat was placed into the box. The litter tray was emptied and cleaned with acetic acid solution at the end of each day.

\section{Data Analyses}

The dependent measures were first analyzed with between-group one-way analyses of variance (ANOVAs) or repeated measures ANOVAs. Post hoc contrasts prompted by statistically significant interactions were performed with Student-Newman-Keuls tests. Statistical significance for all tests was declared with a two-tailed $\alpha$ of .05 .

\section{Results}

\section{Experiment 1}

Figure 1A shows the mean saccharin intake across the eight conditioning trials regardless of context (black or white) for rats treated with either morphine $(2 \mathrm{mg} / \mathrm{kg})$ or saline. The repeated measures ANOVA revealed a main effect of trial, $F(7,91)=7.79$, and a significant Trial $\times$ Drug (saline vs. morphine) interaction, $F(7,91)=4.60$. The main effect of drug approached statistical significance, $F(1,13)=3.53, p>.08$.
The post hoc Student-Newman-Keuls tests indicated that saccharin consumption was higher in the morphine-treated rats on the first saccharin trial. This pattern reversed later, with morphine-treated rats consuming significantly less saccharin than saline-treated rats on Trials 5, 6, and 8 .

Because saccharin exposure could interact with the unconditioned effects of morphine (e.g., Bergmann, Cohen, \& Lieblich, 1984; Bowers, Nicastle, \& Falb, 1993), we assessed whether activity in the white boxes interacted with the fluid type (water or saccharin) that was available on a given trial. Fluid type did not interact with drug or trial, $F \mathrm{~s}<1.24$; the Fluid $\times$ Drug $\times$ Trial interaction also was not significant, $F<$ 1. Hence, for ease of presentation, $B$ shows the activity in the white test box for morphine- and saline-injected rats regardless of fluid type. As expected, morphine increased activity with repeated administration. We found a main effect of drug, $F(1,13)=112.72$, a main effect of trail, $F(7,91)=3.31$, and a significant Drug $\times$ Trial interaction, $F(7,91)=4.66$. Post hoc comparisons revealed that the morphine-injected rats were more active than the saline-injected rats on all but Trial 1 .

Figure 2A shows each group's saccharin consumption for the 75-min CS-alone test. Saccharin consumption did not differ
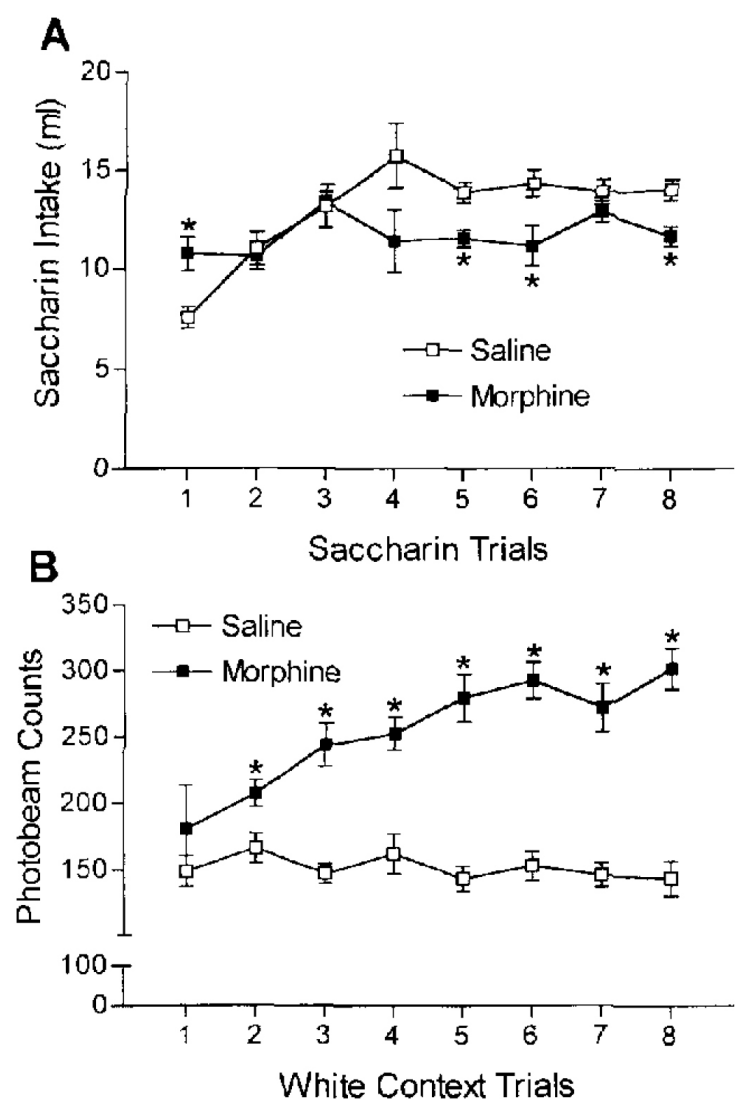

Figure 1. (A) Mean saccharin consumption ( \pm 1 SEM) for rats in Experiment 1 regardless of box (white or black). The morphine dose was $2 \mathrm{mg} / \mathrm{kg}$. (B) Activity ( \pm 1 SEM) of morphine- versus saline-treated rats across conditioning trials in the white locomotor box. Asterisks denote a significant difference $(p \leq .05)$ between groups. 

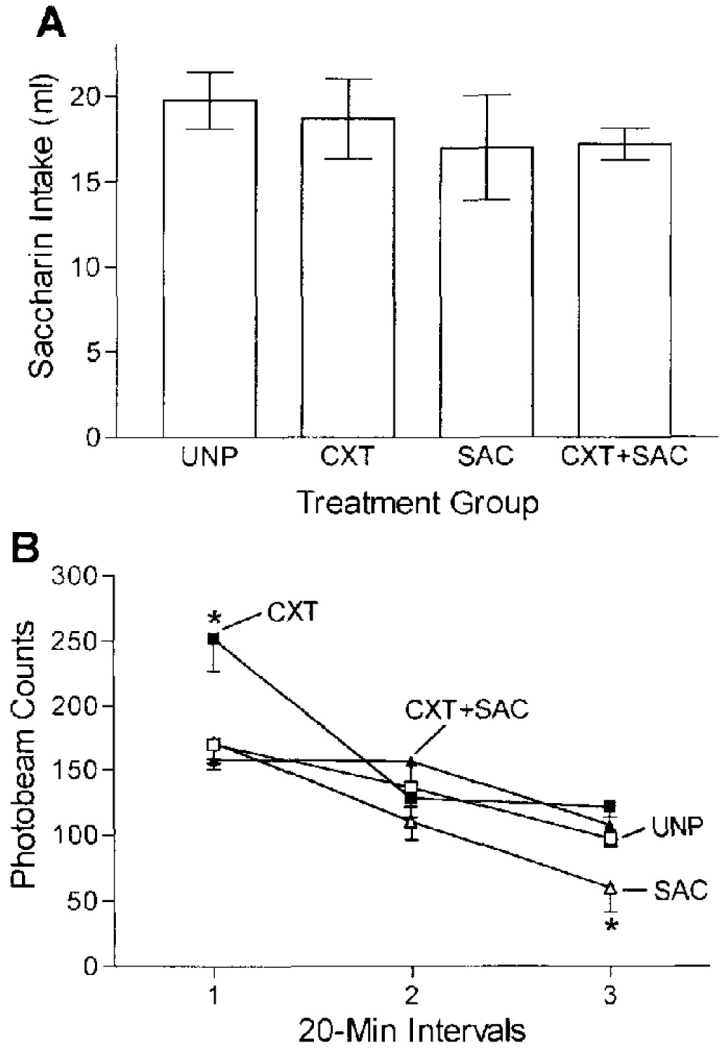

Figure 2. (A) Saccharin intake ( \pm 1 SEM) during the 75-min CS-alone test for each treatment group in Experiment 1. (B) Last 60 min of activity ( -1 SEM) in the white box in the test session for each of the treatment groups, shown in 20-min intervals. Asterisks denote a significant difference $(p \leq .05)$ from the values for the explicitly unpaired control group. $\mathrm{UNP}=$ unpaired; $\mathrm{CXT}=$ white context; $\mathrm{SAC}=$ saccharin.

statistically among the groups, $F<1$. However, groups showed significant differences in locomotor activity on the test day ( B). Recall that on the test day, photobeam counts were recorded for $15 \mathrm{~min}$, the counters were reset, and activity was measured for an additional $60 \mathrm{~min}$. Activity in the first $15 \mathrm{~min}$ of testing did not differ among the groups, $F(3$, $11)=1.44$ (data not shown). B shows the remaining activity data in three 20 -min blocks. Overall, activity decreased across the test session. We found a main effect of group, $F(3,11)=$ 3.70 , a main effect of interval, $F(2,22)=57.76$, and a significant Group $\times$ Interval interaction, $F(6,22)=5$.16. Subsequent comparisons prompted by the interaction revealed that group CXT was more active than all the other groups in the first 20min interval displayed. Thus, contextual cues (white box) reliably paired with morphine $(2 \mathrm{mg} / \mathrm{kg})$ elicited a transient hyperactive $\mathrm{CR}$. Interestingly, group SAC was less active than all the other groups in the last $20 \mathrm{~min}$ of testing. This latter result suggests that a saccharin taste paired with morphine acquired the ability to elicit a hypoactive CR. The lack of a difference between group CXT+SAC and group UNP is consistent with this latter suggestion. That is, perhaps for group $\mathrm{CXT}+\mathrm{SAC}$, the hypoactivity evoked by the saccharin CS in- terfered with the hyperactivity evoked by the context (see discussion later in the article).

Experiments $2 a, 2 b$, and $2 c$

Figure $3 \mathrm{~A}$ shows saccharin consumption across the eight saccharin conditioning trials for each of the morphine doses examined. The 2- and 4-mg/kg induced weak and transient avoidance of the saccharin solution. However, the $8-\mathrm{mg} / \mathrm{kg}$ dose produced robust saccharin avoidance. Separate analyses at each dose supported these observations. For the 2- and 4$\mathrm{mg} / \mathrm{kg}$ morphine doses, there was a significant Trial $\times$ Group interaction, $F \mathrm{~s}(7,126)>2.60$; the main effects of group, $F \mathrm{~s}(1$, $18)<2.27$, and of trial, $F_{\mathrm{s}}(7,126)<1.61$, were not significant. For the $8-\mathrm{mg} / \mathrm{kg}$ morphine dose, the main effects of group, $F(1,18)=19.66$, and of trial, $F(7,126)=2.93$, and the interaction, $F(7,126)=9.51$, were significant. Student-Newman-Keuls tests on the $2-\mathrm{mg} / \mathrm{kg}$ data revealed less saccharin consumption for group paired than for group unpaired on Trials 1 and 7, whereas group paired drank less saccharin than group unpaired on Trials 3 and 6 when treated with $4 \mathrm{mg}$ of morphine per $\mathrm{kg}$. At the $8-\mathrm{mg} / \mathrm{kg}$ morphine dose, group paired consumed less saccharin than did group unpaired on Trials 2 to 8 .
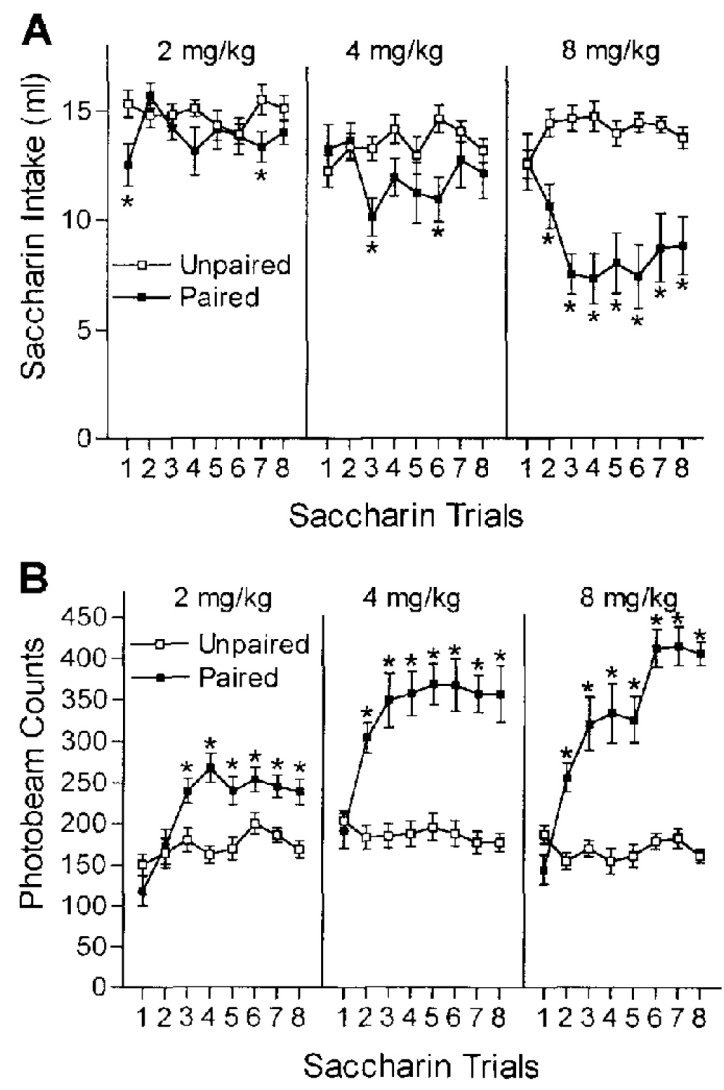

Figure 3. (A) Saccharin intake ( \pm 1 SEM) across conditioning trials for Experiments 2a, 2b, and 2c (i.e., 2, 4, and $8 \mathrm{mg}$ of morphine per $\mathrm{kg}$, respectively). (B) Activity data ( \pm 1 SEM) across saccharin trials. Asterisks denote a significant difference $(p \leq .05)$ from the values for the unpaired control group. 
On the saccharin trials, all doses of morphine induced increases in activity after repeated administration (Figure 3B). ${ }^{1}$ The degree of hyperactivity appeared directly related to the dose of morphine. At each dose, the ANOVA revealed main effects of group, $F_{\mathrm{s}}(1,18) \geq 9.00$, and of trial, $F \mathrm{~s}(7,126)>$ 8.03 , as well as a significant Group $\times$ Trial interaction, $F \mathrm{~s}(7$, 126) $>8.53$. Subsequent contrasts were conducted at each dose of morphine. When compared with group unpaired, group paired evidenced morphine-induced hyperactivity with $2 \mathrm{mg} / \mathrm{kg}$ on Trials 3 to 8 . The two higher morphine doses (4 and $8 \mathrm{mg} / \mathrm{kg}$ ) induced hyperactivity on all but the first saccharin trial.

One issue that requires some attention before the test results for Experiments 2a, 2b, and $2 \mathrm{c}$ are presented is the possible interaction between activity and saccharin consumption. In general, rats that received the highest dose of morphine (8 $\mathrm{mg} / \mathrm{kg}$ ) were more active and consumed less saccharin than rats treated with the lower doses. This trend suggests that the avoidance of the saccharin solution shown in A may have been due to morphine-induced hyperactivity interfering with drinking. An alternative possibility is that saccharin acquired conditioned aversive properties as a result of being paired with morphine. For three reasons, the first possibility seems unlikely. First, the hyperactivity induced by the 4-mg/kg dose of morphine approximated the hyperactivity seen with the $8-\mathrm{mg} /$ $\mathrm{kg}$ dose. In comparison with the $8-\mathrm{mg} / \mathrm{kg}$ group, however, the $4-\mathrm{mg} / \mathrm{kg}$ group showed weak saccharin avoidance. The second reason arguing against the notion of morphine-induced hyperactivity interfering with saccharin consumption can be found on the intervening water days. Group unpaired received morphine on the water days, whereas group paired received saline. Although morphine-induced locomotor sensitization was observed for all doses on the water days, water consumption did not differ statistically between groups (paired vs. unpaired) at any of the doses (data not shown). The largest $F$ value for the main effect of group or the Group $\times$ Trial interaction was $1.34, p=.24$. Thus, the decrease in saccharin intake seen during conditioning trials in Experiments 1, 2a, 2b, and 2c more likely reflects conditioned saccharin avoidance. Finally, on the test day on which the saccharin CS was presented alone, conditioned saccharin aversion was evident only at the $8-\mathrm{mg} / \mathrm{kg}$ dose of morphine (A). One-way ANOVAs found no significant difference in saccharin consumption between groups at the $2-$ or $4-\mathrm{mg} / \mathrm{kg}$ morphine dose, $F \mathrm{~s}<2.15$. However, group paired drank significantly less saccharin than did group unpaired at the $8-\mathrm{mg} / \mathrm{kg}$ dose, $F(1,16)=16.00$. $^{2}$

Regardless of morphine dose, locomotor activity did not differ among groups in the first $15 \mathrm{~min}$ of the test session, $F_{\mathrm{S}}$ $<1$ (data not shown). B shows the photobeam counts from the last 60 min of the 75-min test session for each morphine dose. As in Experiment 1, a saccharin taste previously paired with morphine elicited a decrease in activity relative to that in the control group. This hypoactive CR appeared stronger at the 2and $4-\mathrm{mg} / \mathrm{kg}$ doses of morphine than at the $8-\mathrm{mg} / \mathrm{kg}$ dose. For the $2-\mathrm{mg} / \mathrm{kg}$ experiment, we found a main effect of interval,
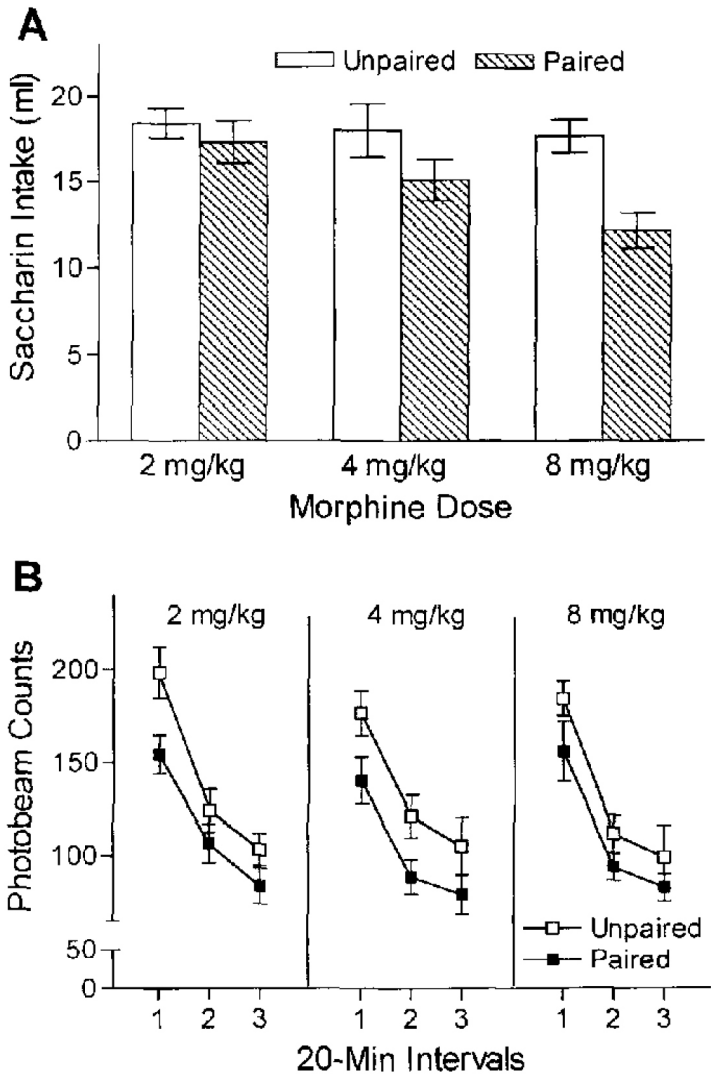

Figure 4. (A) Saccharin intake $( \pm 1$ SEM) on the CS-alone test day for each group in Experiments 2a, 2b, and 2c. (B) Last 60 min of activity ( \pm 1 SEM) in the test session for group paired versus group unpaired at each dose, shown in 20-min intervals

$F(2,36)=73.81$, denoting a decrease in activity across the test, and a main effect of group, $F(1,18)=4.49$, representing overall less activity in group paired than in group unpaired. The Group $\times$ Interval interaction was not significant, $F(2,36)$ $=2.16$. The pattern of results was similar at the $4-\mathrm{mg} / \mathrm{kg}$ dose. We found a main effect of interval, $F(2,36)=28.73$, and of group, $F(1,18)=5.55$; the interaction was not significant, $F<$ 1. In contrast, only the main effect of interval was significant at the $8-\mathrm{mg} / \mathrm{kg}$ dose of morphine, $F(2,34)=47.40$; there was no main effect of group, $F(1,17)=2.46$, and the Group $\times$ Interval interaction was not significant, $F<1$.

\footnotetext{
${ }^{1}$ In Experiments 2a to 2c, data for several rats were lost on a given trial as a result of mechanical or technical errors. The statistical package used to analyze the data (SAS) drops the entire animal from the analysis when one value from the repeated measures is missing, resulting in an unacceptable loss of data. To avoid this problem, we derived an estimate for missing values by using the mean for values of the trials before and after the missing value. For example, activity on the second saccharin trial for a morphine-paired rat in Experiment 2a was lost. We placed a value of 209 photobeam counts into the empty cell of the analysis. This value was the mean of activities on saccharin Trial 1 (175 counts) and Trial 3 (243 counts).

${ }^{2}$ In Experiment 2c (8- $\mathrm{mg} / \mathrm{kg}$ morphine dose), saccharin intake data on the test day were lost for one rat in group paired and for one rat in group unpaired. Also, a photobeam bulb went out during testing for a rat in group unpaired. The statistical analyses and Figure 4 reflect these losses.
} 


\section{Experiment 3}

As in the previous experiments with a saccharin taste CS, when a banana odor was used as the CS, morphine $(2 \mathrm{mg} / \mathrm{kg})$ induced hyperactivity after repeated injections (A). We found a main effect of trial, $F(7,126)=24.09$, and a significant Group $\times$ Trial interaction, $F(7,126)=5.15$. The main effect of group approached statistical significance, $F(1,18)=4.18, p=$ .056. Subsequent Student-Newman-Keuls tests at each trial revealed greater activity in group paired than in group unpaired on Trials 4, 6, and 8 .

Unlike a taste CS, but similar to a context CS (Figure 2B), an olfactory cue reliably paired with morphine elicited a hyperactive CR. B shows the activity counts in 10-min intervals for the 30-min test session. There was a main effect of group, $F(1,18)=6.27$, denoting that group paired was more active than group unpaired. The general decrease in activity across the test session was evident by a main effect of interval, $F(2$, $36)=86.68$. The Group $\times$ Interval interaction was not significant, $F(2,36)=1.78$.

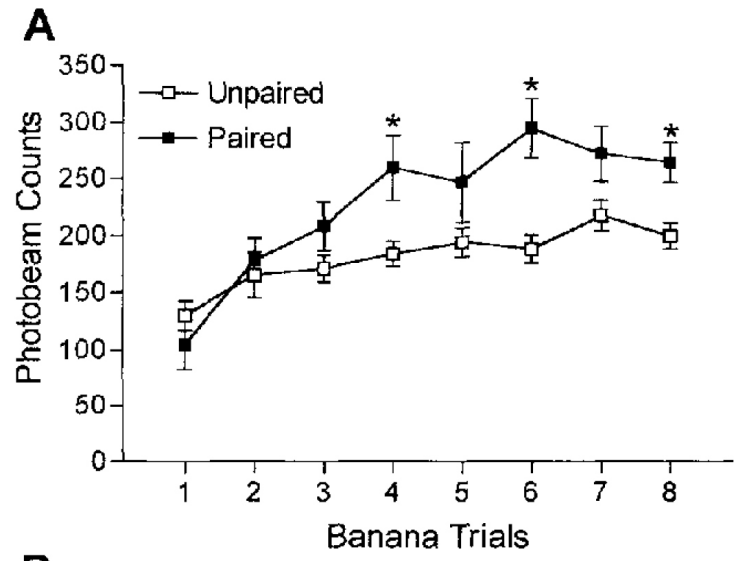

B

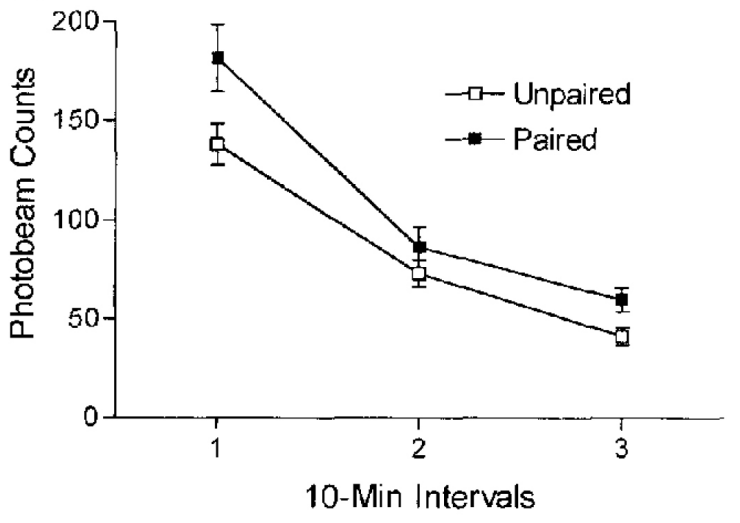

Figure 5. (A) Activity ( \pm 1 SEM) across banana odor conditioning trials for each group in Experiment 3 (2 $\mathrm{mg}$ of morphine per kg or saline). (B) Test session activity ( \pm 1 SEM) in 10-min intervals when the banana odor CS was presented alone. Asterisks denote a significant difference $(\mathrm{p} \leq .05)$ from the values for the unpaired control group.

\section{Discussion}

Like other researchers (e.g., Babbini \& Davis, 1972), we found that morphine-induced activity increased with repeated injections. Also as in previous work (e.g., Neisewander \& Bardo, 1987), when morphine administration was reliably paired with a distinct set of contextual cues, those cues, in the absence of drug, elicited increases in activity (hyperactive $\mathrm{CR}$ ). Our experiments extend these findings by examining the effect of a discrete taste or odor cue on morphine locomotor activity conditioning. In particular, when an olfactory cue (banana odor) was reliably paired with morphine, that odor CS elicited a hyperactive CR. Yet, when a gustatory cue (saccharin solution) served as the CS, a hypoactive CR occurred. This taste-elicited decrease in activity was dose dependent. Pairing the taste with either the 2- or the 4-mg/ $\mathrm{kg}$ morphine dose conditioned a hypoactive $\mathrm{CR}$, whereas the $8-\mathrm{mg} / \mathrm{kg}$ dose resulted in no significant difference in activity relative to that in the control group. This latter result was probably attributable to the decrease in saccharin CS exposure from the taste aversion induced by the $8-\mathrm{mg} / \mathrm{kg}$ dose of morphine (see McAllister, McAllister, \& Dieter, 1976, for the biphasic effect of increasing US intensity). Finally, the taste CS was able to interfere with either the acquisition or the expression of the hyperactive $\mathrm{CR}$ in response to context. That is, rats that had a context and a taste reliably paired with morphine did not differ from control rats (no pairing). This latter result is consistent with a behavioral mixing account of stimulus compounding (Weiss, 1972). That account would argue that the increase in activity controlled by the contextual cue competed with the decrease in activity controlled by the taste cue. Thus, the competing response types canceled each other out.

The results of this study clearly demonstrate that the nature of the CS is, at least in part, a determinant of the form of the $\mathrm{CR}$ in a locomotor conditioning paradigm with a morphine US. Studies done with other Pavlovian conditioning preparations and nondrug USs have reported similar effects of CS type on the CR form. In a now classic study, Holland (1977) reported that in an appetitive conditioning situation with rats, a tone CS elicited startle and head-jerk CRs; yet, a visual CS (light) elicited rearing and food tray orienting. Stimulus modality also affected the CR form in Pavlovian aversive conditioning of rats with a foot-shock US (Bevins \& Ayres, 1991; Kim, Rivers, Bevins, \& Ayres, 1996).

The notion of different stimulus modalities acquiring the ability to elicit different CR forms given the same US has several important implications for drug conditioning work. For example, locomotor conditioning studies typically use diffuse contextual cues comprising a complex of stimuli including visual, auditory, olfactory, thermal, tactile, and gustatory elements. Thus, in conditioning, any one or some combination of these stimuli may acquire the conditioned strength. Importantly, the behavior controlled by one stimulus element may interfere with or facilitate the CR to another element present on the test day. The presence of competing CR forms, along 
with inconsistencies in day-to-day stimuli that comprise the context, could explain individual differences in conditioned drug responding (Jodogne, Marinelli, LeMoal, \& Piazza, 1994; Schwarz-Stevens \& Cunningham, 1993).

It may be argued that the hypoactive CR elicited by the taste CS in this study is not relevant to other demonstrations of drug-induced locomotor conditioning because gustatory stimuli are not experienced in a typical context. Although standard contextual CS used in this area of research do not contain an explicit gustatory stimulus like that used in this study, we would argue that gustatory stimuli can be readily experienced within any context. For instance, rats probably receive gustatory input when grooming themselves or when licking and biting the apparatus. Interestingly, many of the drugs used in the locomotor conditioning paradigm alter these behaviors (Arnt, Hyttel, \& Perregaard, 1987; Ferger \& Kuschinsky, 1995; Hiroi \& White, 1989; Segal \& Kuczenski, 1994). Thus, not only do taste cues exist in a typical context, but also the degree of exposure to those cues during conditioning and testing depends on the drug treatment (cf. Overton, 1964).

One possible reason that taste may have evoked a different CR than either context or odor is that taste is a highly localized CS, whereas the context and the odor CS used in this work were diffuse. Holland (1980) found that a highly localized light CS paired with food elicited a CR directed toward the CS, whereas a diffuse light CS elicited behaviors directed at the food tray. Holland suggested that it was the orienting response to the CS that determined the CR form in his conditioning situation. A similar argument could be made for our results. To experience the taste $\mathrm{CS}$, the rats remain relatively stationary while contacting the sipper tube (i.e., decreased locomotor behavior). The odor and context CS, in general, do not require a specific orienting response that discourages movement. Perhaps if the CS does not elicit a strong or directed orienting response, the US has more influence over the nature of the CR (see Davey \& Cleland, 1982; Jenkins \& Moore, 1973). Future research directed at this question could test this account by removing the response-contingent nature of the taste CS used in this work. Rather than requiring the rat to approach and drink the saccharin solution, the fluid could be infused directly into the mouth with an intraoral cannula. This manipulation would allow the taste CS, like the odor CS, to be experienced without a directed response.

Finally, most theories of drug abuse and addiction invoke conditioning mechanisms to explain some aspect of drug seeking, drug taking, and/or relapse (O’Brien et al., 1992; Ramsay \& Woods, 1997; Robinson \& Berridge, 1993; Siegel, 1988; Stewart, 1992a; Wise \& Bozarth, 1987). This study clearly demonstrates the ability of repeated drug administration to condition stimuli that are reliably present. Not only will the place at which a person readily takes drugs acquire associative strength (i.e., context), but also very specific stimulus elements within that context may acquire associative strength (e.g., paraphernalia). Thus, the discrete olfactory, gustatory, tactile, visual, auditory, and thermal cues experienced in conjunction with the drug may acquire the ability to evoke a CR similar to or different from that evoked by the drug itself, depending on the stimulus type. Intervention strategies may change depending on the effective stimuli for a given individual.

\section{References}

Arnt, J., Hyttel, J., \& Perregaard, J. (1987). Dopamine D-1 receptor agonists combined with the selective D-2 agonist quinpirole facilitate the expression of oral stereotyped behaviour in rats. European Journal of Pharmacology, 133, 137-145.

Ayres, J. J. B., Philbin, D., Cassidy, S., Bellino, L., \& Redlinger, E. (1992). Some parameters of latent inhibition. Learning \& Motivation, 23, 268-287.

Babbini, M., \& Davis, W. M. (1972). Time-dose relationships for locomotor activity effects of morphine after acute or repeated treatment. British Journal of Pharmacology, 46, 213-224.

Bergmann, F., Cohen, E., \& Lieblich, I. (1984). Biphasic effects of chronic saccharin intake on pain responses of healthy and diabetic rats of two genetically selected strains. Psychopharmacology, 82, 248-251.

Bevins, R. A., \& Ayres, J. J. B. (1991). Two issues in Pavlovian fear conditioning: Selective fear of bright vs. dark, and CS determinants of CR form. Behavioural Processes, 24, 211-218.

Bowers, R. L., Nicastle, L. D., \& Falb, D. C. (1993). Saccharin effects on morphine-induced temperature change in rats. Pharmacology Biochemistry and Behavior, 46, 483-485.

Davey, G. C. L., \& Cleland, G. G. (1982). Topography of signal-centered behavior in the rat: Effects of deprivation state and reinforcer type. Journal of the Experimental Analysis of Behavior, 38, 291-304.

Ferger, B., \& Kuschinsky, K. (1995). A comparison of different sensory stimuli in producing conditioned apomorphine effects. Behavioural Pharmacology, 6, 40-45.

Hiroi, N., \& White, N. M. (1989). Conditioned stereotypy: Behavioral specification of the UCS and pharmacological investigation of the neural change. Pharmacology Biochemistry and Behavior, 32, 249-258.

Holland, P. C. (1977). Conditioned stimulus as a determinant of the form of the Pavlovian conditioned response. Journal of Experimental Psychology: Animal Behavior Processes, 3, 77-104.

Holland, P. C. (1980). Influence of visual conditioned stimulus characteristics on the form of Pavlovian appetitive conditioned responding in rats. Journal of Experimental Psychology: Animal Behavior Processes, 6, 81-97.

Jenkins, H. M., \& Moore, B. R. (1973). The form of the autoshaped response with food and water reinforcers. Journal of the Experimental Analysis of Behavior, 20, 163-181.

Jodogne, C., Marinelli, M., LeMoal, M., \& Piazza, P. V. (1994). Animals predisposed to develop amphetamine self-administration show higher susceptibility to develop contextual conditioning of both amphetamine-induced hyperlocomotion and sensitization. Brain Research, 657, 236-244.

Kalivas, P. W., \& Stewart, J. (1991). Dopamine transmission in the initiation and expression of drug- and stress-induced sensitization of motor activity. Brain Research and Review, 16, $223-244$ 
Kim, S. D., Rivers, S., Bevins, R. A., \& Ayres, J. J. B. (1996). CS determinants of CR form in Pavlovian fear conditioning. Journal of Experimental Psychology: Animal Behavior Processes, 22, 87-104.

Lubow, R. E. (1973). Latent inhibition. Psychological Bulletin, 79, 398-407.

McAllister, D., McAllister, W., \& Dieter, S. (1976). Reward magnitude and shock variables (continuity and intensity) in shuttlebox-avoidance learning. Animal Learning \& Behavior, 4, 204-209.

Mucha, R. F., Volkovskis, C., \& Kalant, H. (1981). Conditioned increases in locomotor activity produced with morphine as an unconditioned stimulus, and the relation of conditioning to acute morphine effect and tolerance. Journal of Comparative and Physiological Psychology, 95, 351-362.

Neisewander, J. L., \& Bardo, M. T. (1987). Expression of morphineconditioned hyperactivity is attenuated by naloxone and pimozide. Psychopharmacology, 93, 314-319.

O’Brien, C. P., Childress, A. R., McLellan, A. T., \& Ehrman, R. (1992). A learning model for addiction. In C. P. O'Brien \& J. H. Jaffe (Eds.), Addictive states (pp. 157-177). New York: Raven Press.

Overton, D. A. (1964). State-dependent or "dissociated" learning produced with pentobarbital. Journal of Comparative and Physiological Psychology, 57, 3-12.

Pavlov, I. P. (1927). Conditioned reflexes. New York: Dover.

Ramsay, D. S., \& Woods, S. C. (1997). Biological consequences of drug administration: Implications for acute and chronic tolerance. Psychological Review, 104, 170-193.

Rescorla, R. A., \& Wagner, A. R. (1972). A theory of Pavlovian conditioning: Variations in the effectiveness of reinforcement and nonreinforcement. In A. H. Black \& W. F. Prokasy (Eds.), Classical conditioning II: Current research and theory (pp. 64-99). New York: Appleton-Century-Crofts.

Robinson, T. E., \& Berridge, K. C. (1993). The neural basis of drug craving: An incentive-sensitization theory of addiction. Brain Research and Reviews, 18, 247-291.
Schulteis, G., \& Koob, G. F. (1996). Reinforcement processes in opiate addiction: A homeostatic model. Neurochemical Research, $21,1437-1454$.

Schwarz, K. S., \& Cunningham, C. L. (1990). Conditioned stimulus control of morphine hyperthermia. Psychopharmacology, 101, $77-84$.

Schwarz-Stevens, K. S., \& Cunningham, C. L. (1993). Pavlovian conditioning of heart rate and body temperature with morphine: Effects of CS duration. Behavioral Neuroscience, 107, 1039-1048.

Segal, D. S., \& Kuczenski, R. (1994). Behavioral pharmacology of amphetamine. In A. K. Cho \& D. S. Segal (Eds.), Amphetamine and its analogs: Psychopharmacology, toxicology, and abuse (pp. 115-150). New York: Academic Press.

Siegel, S. (1988). Drug anticipation and drug tolerance. In M. Lader (Ed.), The psychopharmacology of addiction (pp. 73-97). New York: Oxford University Press.

Stewart, J. (1992a). Conditioned stimulus control of the expression of sensitization of the behavioral activating effects of opiate and stimulant drugs. In I. Gormezano \& E. A. Wasserman (Eds.), Learning and memory: The behavioral and biological substrates (pp. 129-151). Hillsdale, NJ: Erlbaum.

Stewart, J. (1992b). Neurobiology of conditioning to drugs of abuse. Annals of the New York Academy of Sciences, 654, 335-346.

Vezina, P., \& Stewart, J. (1987). Conditioned locomotion and place preference elicited by tactile cues paired exclusively with morphine in an open field. Psychopharmacology, 91, 375-380.

Weiss, S. J. (1972). Stimulus compounding in free-operant and classical conditioning: A review and analysis. Psychological Bulletin, 78, 189-208.

Wise, R. A., \& Bozarth, M. A. (1987). A psychomotor stimulant theory of addiction. Psychological Review, 94, 469-492. 